\title{
Prostatic adenocarcinoma evolving into carcinoid: selective effect of hormonal treatment?
}

\author{
M STRATTON, $\dagger$ DJ EVANS, $\dagger$ IA LAMPERT*† \\ From the *Department of Histopathology, Ealing Hospital, and $\dagger$ The Royal Postgraduate Medical School, \\ London
}

SUMmaRY Two patients, aged 72 and 65 years, each underwent two prostatic resections spaced four and two years apart, respectively. In both cases the earlier procedure showed widespread adenocarcinoma with only occasional endocrine cells, while tissue from the later operations showed prostatic carcinoids.

It is suggested that the conventional adenocarcinomas were sensitive to hormonal manipulations of used in treatment, but that the originally sparse carcinoid components were resistant to this form of $\frac{\mathrm{O}}{\supset}$ treatment and hence became the predominant tumours. These findings imply that endocrine differentiation in prostatic carcinoma leads to lack of sex steroid sensitivity.

Endocrine cells comprise part of the epithelium of normal and hyperplastic prostate. ${ }^{1-3}$ Moreover, they are present in up to $30 \%$ of prostatic adenocarcinomas, ${ }^{3}$ ranging from occasional cells to a substantial proportion, and occasionally all of the tumour mass. ${ }^{45}$ Their presence may be responsible for endocrine syndromes associated with tumours, ${ }^{67}$ and hormones have been confirmed immunohistochemically. ${ }^{367}$ There is, however, no published data relating to the steroid sensitivity and hence responsiveness of these tumours to treatment. The cases presented here of prostatic adenocarcinomas, which develop into carcinoids under hormonal treatment, suggest that neoplastic prostatic endocrine cells may lack the profile of steroid sensitivity that is characteristic of the bulk of normal prostatic epithelium and many prostatic adenocarcinomas.

\section{Case reports}

CASE 1

A 72 year old man presented with symptoms of bladder outflow obstruction. Clinical examination showed a hard irregular prostate and an enlarged left supraclavicular lymph node. His acid phosphatase activity was raised at $>50 \mathrm{IU} / 1$ (normal $<1.4 \mathrm{IU} / \mathrm{l})$. A clinical diagnosis of prostatic adenocarcinoma was confirmed by needle biopsy. Transurethral prostatic resection

Accepted for publication 6 February 1986 was performed, together with bilateral subcapsular orchidectomy and lymph node biopsy, the latter showing metastatic adenocarcinoma similar to that found in the prostate. Treatment with fosfestrol, $200 \mathrm{mg}$ three times a day (subsequently changed to $\mathbb{\perp}$ stilboestrol, $1 \mathrm{mg}$ ) was started. The symptoms of $\overrightarrow{\vec{P}}$ outflow obstruction resolved, and acid phosphatase activity fell to within normal limits. Follow up over the next four years detected no further tumour metastasis, but towards the end of this period he began to experience recurrence of prostatic symptoms, and a ? transurethral resection was performed.

CASE 2

A 65 year old man presented with a 10 month history of rectal pain and frequency of micturition. Clinical 옥 examination showed an enlarged craggy prostate, and $\supset$ blood chemistry showed raised acid phosphatase activity. A transurethral prostatic resection was per- N formed in conjunction with bilateral orchidectomy. Histological examination of the surgical specimen $N$ confirmed the clinical diagnosis of prostatic adeno- $\mathbb{W}$ carcinoma, and the patient was subsequently started $\widetilde{O}$ on stilboestrol, $10 \mathrm{mg}$ three times a day.

Over the ensuing two years he remained generally well, but gradually the symptoms of urinary outflow $\stackrel{?}{?}$ obstruction returned. Rectal examination at this time $\square$ showed that the tumour had invaded locally, fixing the bladder and rectum. At cystoscopy a vesical calcu- $\stackrel{\mathbb{D}}{\Omega}$ lus was found, hence suprapubic prostatic resection $\stackrel{\varnothing}{\varnothing}$ and lithotomy were undertaken. 


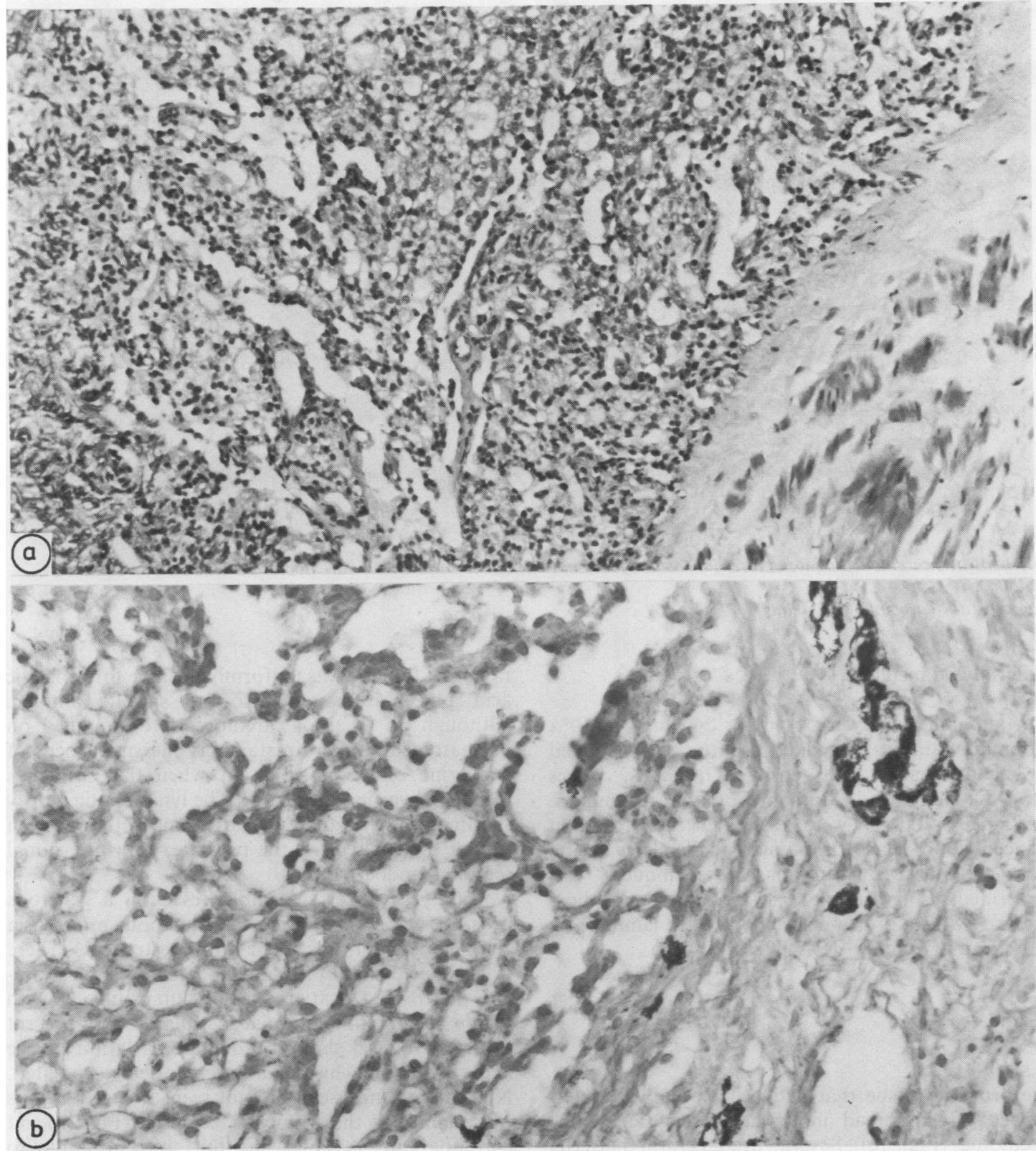

Fig. 1 Case 1

(a) Original prostatic carcinoma. (Haematoxylin and eosin.) $\times 150$;

(b) original prostatic carcinoma with focus of endocrine cells. (Grimelius) $\times 400$. 


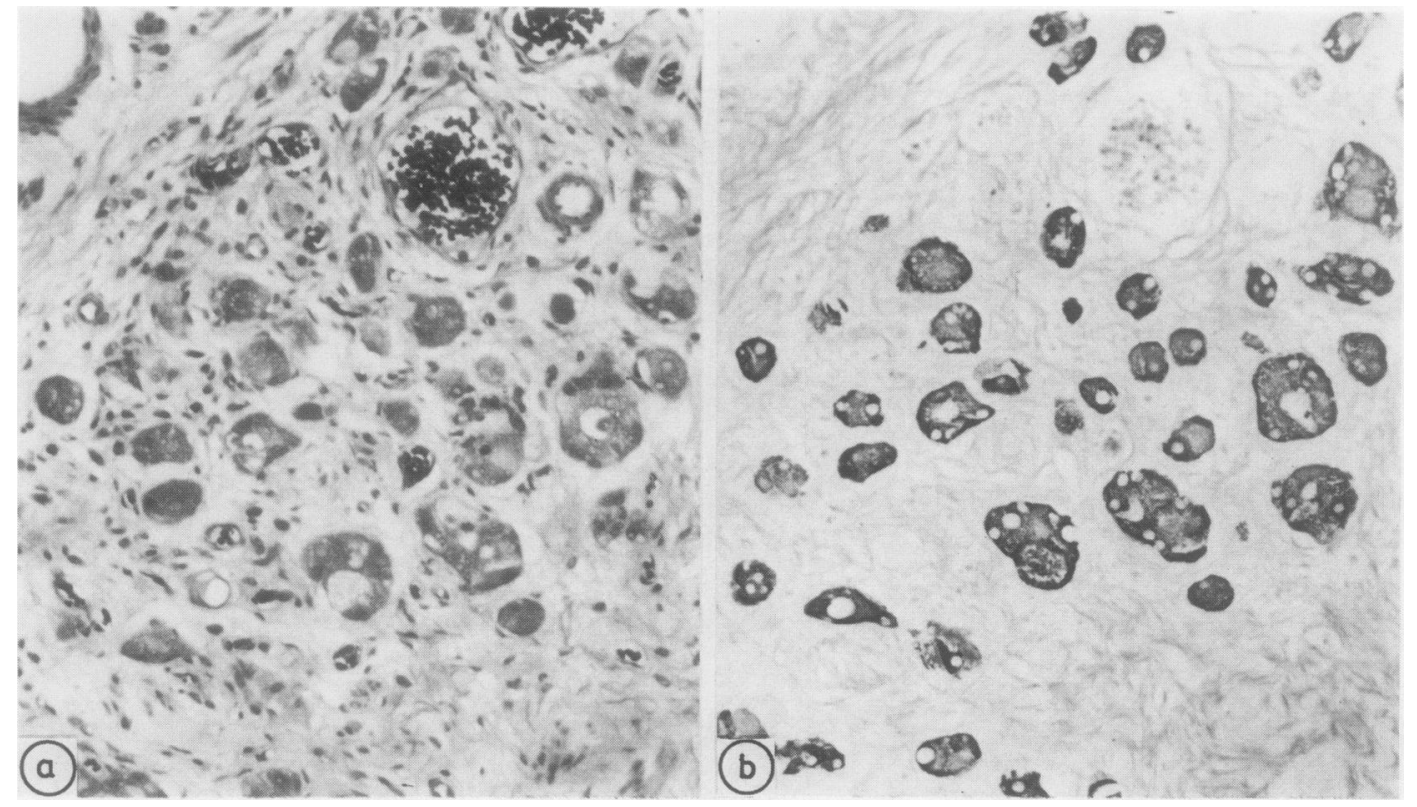

Fig. 2 Case 1

(a) Prostatic carcinoid diagnosed after four years hormonal treatment for prostatic carcinoma. (Haematoxylin and eosin.) $\times 150$;

(b) prostatic carcinoid (Grimelius) $\times 150$.

\section{Material and methods}

Prostatic chippings were fixed for 24 hours in $10 \%$ formalin. Paraffin embedded sections were stained by haematoxylin and eosin, Grimelius, Glees and Marsland, and Masson Fontana techniques. Unstained sections were examined for formalin induced fluorescence. Immunohistochemistry, using the peroxidase-antiperoxidase technique, was performed, using antibodies to prostatic acid phosphatase (Miles), prostate specific antigen (Immulok), and chromogranin A (RIA, UK).

\section{Results}

CASE 1

The prostatic tissue that had been initially resected showed a widespread infiltrating prostatic adenocarcinoma (Fig. 1a). Several architectural patterns were present, ranging from sheet like solid masses of cells to glandular and cribriform areas with zones of single cell infiltration. Cytologically, the tumour was characterised by cells with indistinct borders, eosinophilic vacuolated cytoplasm, and moderately pleomorphic round nuclei with a diffuse chromatin pattern. Nucleoli were inconspicuous and mitoses rare. The tumour was uniformly positive for prostatic acid phosphatase and prostate specific antigen. Although no areas of carcinoid were identified on haematoxylin and eosin staining, one small focus of endocrine cells was apparent when the Grimelius technique was used (Fig. lb). The lymph node biopsy specimen showed an adenocarcinoma with a pattern similar to that seen in the prostate, with occasional scattered endocrine cells.

Four years after the initial resection a generous prostatic resection showed the squamous metaplasia characteristic of treatment with oestrogen. ${ }^{8}$ There was no evidence of the adenocarcinoma seen previously. Instead, scattered small clumps of cells with highly eosinophilic granular cytoplasm were present $\tilde{\sigma}$ (Fig. 2a). Nuclei showed moderate variation in size $N$ and chromatin density and were often vacuolated. N Nucleoli and mitoses were not seen. The cell groups were stained by the Grimelius technique (Fig. 2b) and chromogranin A (Fig. 3a) but were negative to Masson Fontana and did not manifest formalin $\stackrel{\$}{\rightarrow}$ induced fluorescence. Prostatic acid phosphatase staining was uniformly strongly positive (Fig. 3b), and although prostate specific antigen was only $\overrightarrow{\mathbb{D}}$

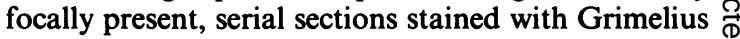
and prostate specific antigen showed cells with positive staining for both (Figs. $3 \mathrm{c}$ and d). 


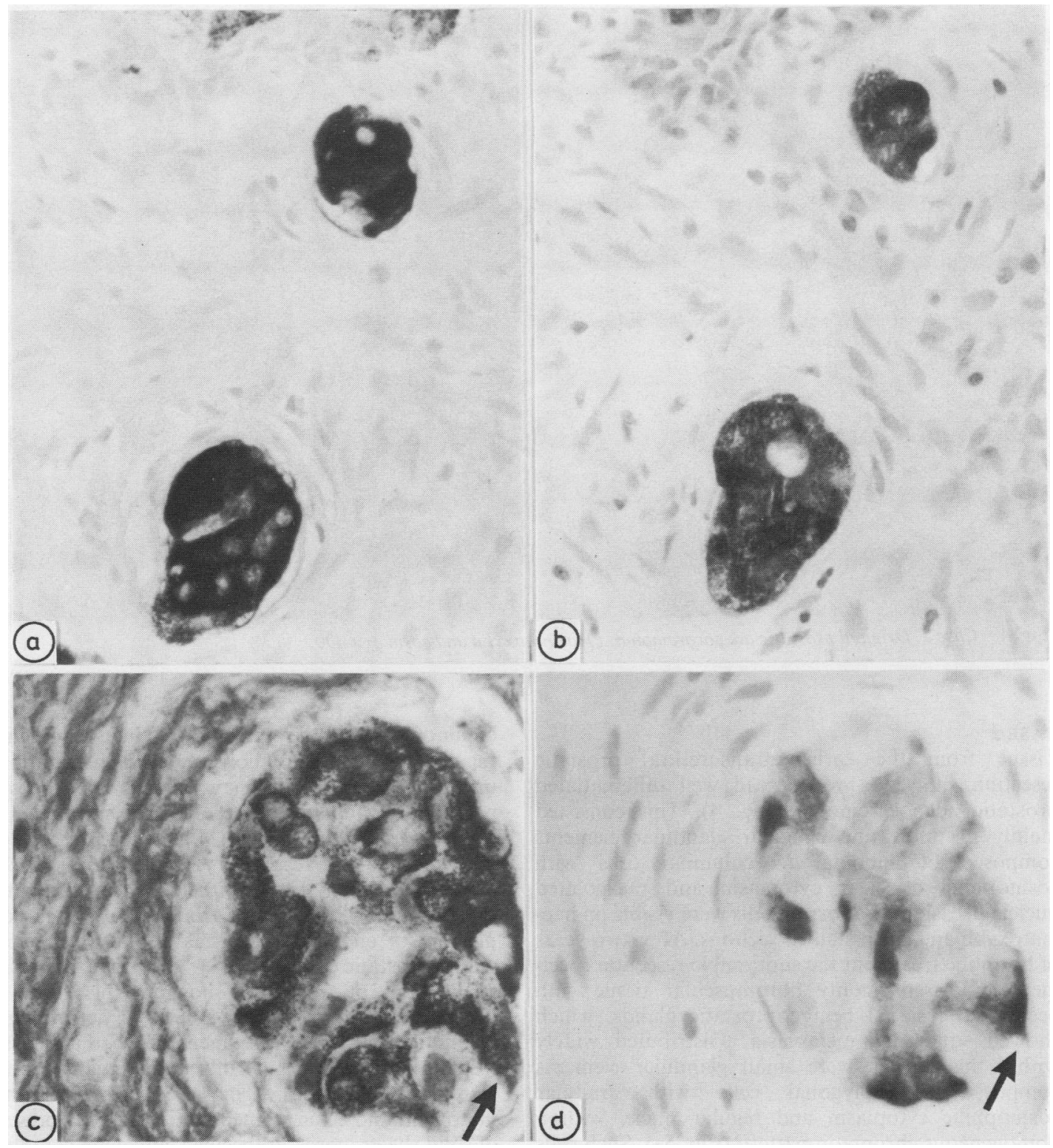

Fig. 3 Case 1

(a) and (b) Serial sections of prostatic carcinoid stained for chromogranin A and prostatic acid phosphatase, respectively. $\times 400$.

(c) and (d) Serial sections of prostatic carcinoid stained for Grimelius and prostate specific antigen, respectively, showing cells positive for both (arrows). $\times 400$. 


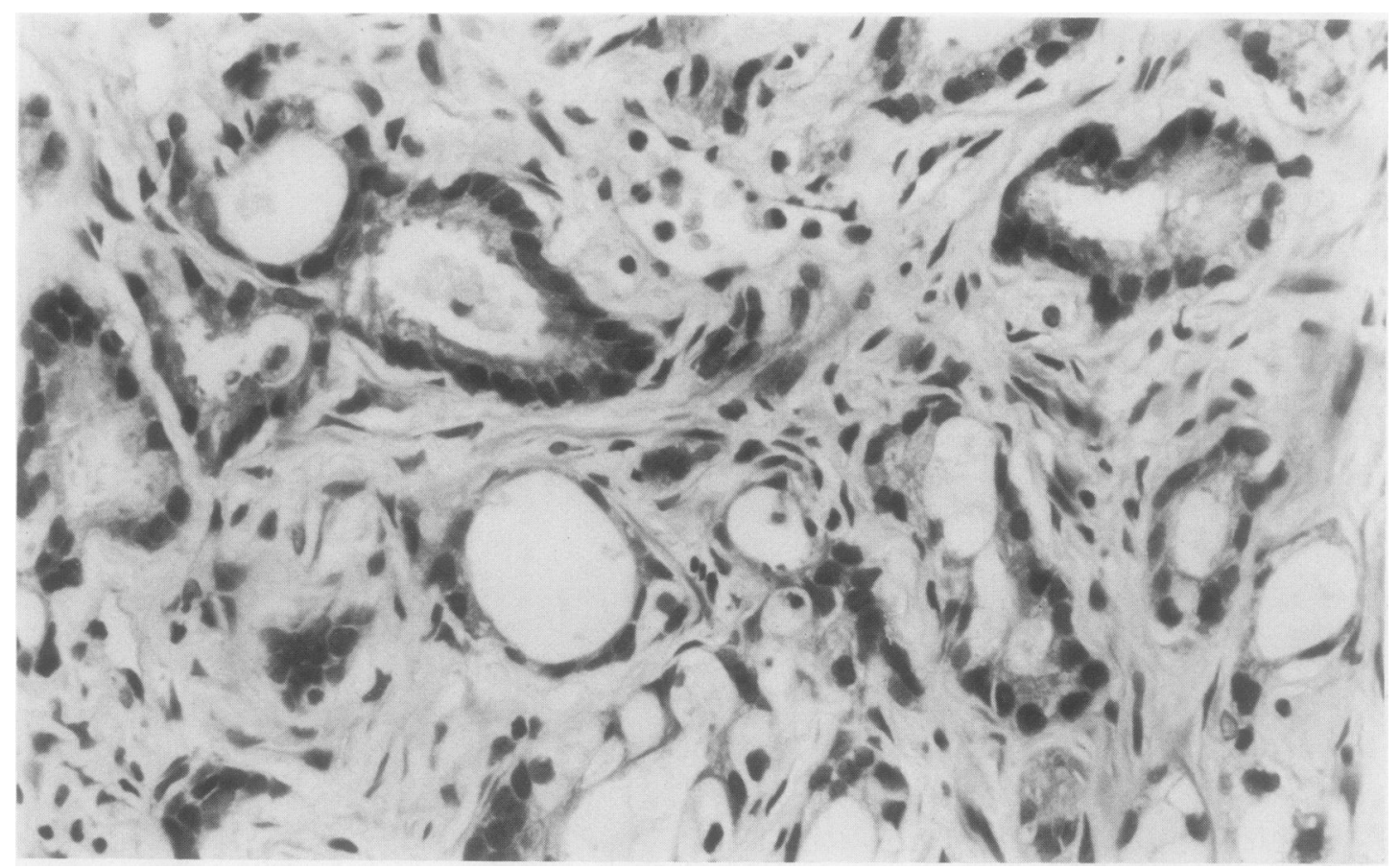

Fig. 4 Case 2. Original prostatic adenocarcinoma. (Haematoxylin and eosin.) $\times 400$.

CASE 2

Tissue from the earlier transurethral prostatic resection showed a widespread well differentiated prostatic adenocarcinoma (Fig. 4). This consisted mainly of infiltrating irregular glandular elements composed of cuboidal to columnar cells with eosinophilic or clear cytoplasm and nucleolated nuclei. Occasional endocrine cells were visible on haematoxylin and eosin stained sections. After two years of hormone treatment the suprapubic resection specimen comprised mainly fibromuscular tissue with occasional residual benign prostatic glands, which showed squamous metaplasia. Distributed widely within this stroma were small glandular elements composed of polygonal cells with granular eosinophilic cytoplasm and regular nuclei with a homogeneous chromatin pattern (Fig. 5a). Such cells showed positivity by the Glees and Marsland technique (Fig. 5c) and stained immunocytochemically for chromogranin A (Fig. 5b).

\section{Discussion}

There are several reports of endocrine cells within normal and hyperplastic prostatic epithelium. ${ }^{1-3}$ Predominantly argyrophil, ${ }^{23}$ they are found most commonly within the epithelium of ducts leading into $\overrightarrow{\vec{O}}$ the urethra. Even here, however, their distribution is 3 uneven, and numbers may vary greatly between neighbouring ducts. ${ }^{12}$ The origin of such cells has? been debated, but the prevailing view, by analogy응 with the gut and respiratory epithelia, is that they : differentiate from local epithelial stem cells rather 3 . than that they migrate in from afar. ${ }^{7910} \mathrm{~A}$ complement of endocrine cells has also been described within prostatic carcinomas. ${ }^{1-31112}$ Estimates of the proportion of tumours showing this form of differentiation vary from $8 \%$ to $30 \%$, depending on techniques used and assessment of whether sparsely distributed cells are part of the malignant process. $\mathcal{O}$ Carcinoid differentiation may be recognised in hae- $N$ matoxylin and eosin stained sections by the presence $N$ of solid sheets, cords, trabeculae, and acini composed $\omega$ of uniform polygonal cells, with central deep staining nuclei and eosinophilic granular cytoplasm. Argyrophil positivity is more common, but $\stackrel{\oplus}{\oplus}$ argentaffin positive tumours have been described. Cushing's syndrome and ectopic secretion of antidiuretic hormone have been described in association $\overrightarrow{\mathbb{D}}$ with prostatic carcinoma, ${ }^{6713}$ and adre- $\frac{\rho}{\mathbb{D}}$ nocorticotrophic hormone and endorphin have been $\unrhd$ shown immunohistochemically in carcinoids. ${ }^{3} 70$ 


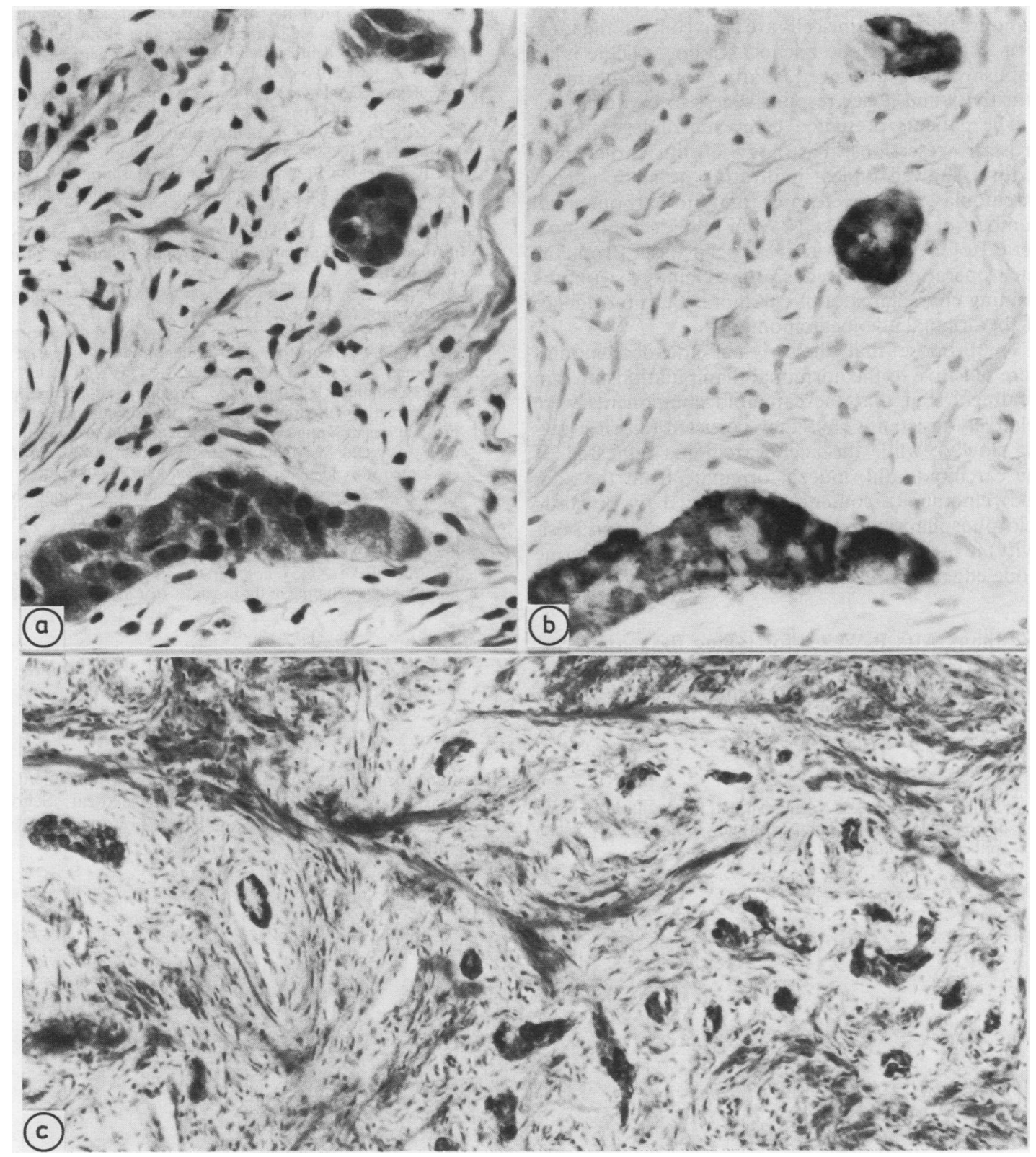

Fig. 5 Case 2

(a) Prostatic carcinoid diagnosed after two years of hormonal treatment for prostatic adenocarcinoma. (Haematoxylin and eosin.) $\times 400$.

(b) prostatic carcinoid (chromogranin A) $\times 400$.

(c) prostatic carcinoid showing wide distribution in fibromuscular stroma. (Glees and Marsland.) $\times 150$. 
Recent reports of prostatic carcinoids staining for prostatic acid phosphatase and prostate specific antigen ${ }^{7} 1012$ further support the notion that in these tumours the endocrine cells are derived from the same stem cells as prostatic adenocarcinoma. There is no published data, however, relating to their hormone sensitivity and hence responsiveness to treatment.

The patients presented here each underwent two prostatic resections. Histology of the earlier procedures showed typical infiltrating prostatic adenocarcinomas, which were later found to harbour small numbers of endocrine cells. After orchidectomy and a period of treatment with oestrogen tissue from the later operations showed scattered clumps with the staining characteristics of carcinoids but no evidence of the original adenocarcinomas.

We propose that the original adenocarcinomas were sensitive to the hormonal manipulations used in treatment, but that the carcinoid components were relatively resistant. Thus they persisted (albeit growing slowly), while the adenocarcinoma regressed. If the carcinoids did, indeed, originate from the adenocarcinomas (a contention supported by prostatic acid phosphatase and prostate specific antigen positivity) it suggests that differentiation in the endocrine mode engenders relative insensitivity to sex steroids.

We thank Mrs $\mathbf{P}$ Weller for typing the manuscript, Mr W Hinkes for photography, and Miss S van Noorden for comments and technical help.

\section{References}

${ }^{1}$ Azzopardi JG, Evans DJ. Argentaffin cells in prostatic carcinoma: differentiation from lipofuscin and melanin in prostatic epithelium. J Pathol 1971;104:247-51.
${ }^{2}$ Kazzaz BA. Argentaffin and argyrophil cells in the prostate. $J$ Pathol 1974;112:189-93.

${ }^{3}$ Capella C, Usellini L, Buffa R, Frigerio B, Solcia E. The endocrine component of prostatic carcinomas, mixed adenocarcinomacarcinoid tumours and non-tumour prostate. Histochemical and ultrastructural identification of the endocrine cells. Histopathology 1981;5:175-92.

${ }^{4}$ Wasserstein P, Goldman R. Primary carcinoid of the prostate. $J$ Urol 1979;13:318-20.

${ }^{5}$ Wasserstein P, Goldman R. Diffuse carcinoid of the prostate. $J$ Urol 1981;18:407-9.

${ }^{6}$ Wenk R, Bhagavan B, Levy R, Miller D, Weisburger N. Ectopic ACTH, prostatic oat cell carcinoma and marked hypernatremia. Cancer 1977;40:773-8.

${ }^{7}$ Ghali V, Garcia R. Prostatic adenocarcinoma with carcinoidal features producing adrenocorticotrophic syndrome. Cancer 1984;54:1043-8.

${ }^{8}$ Bainborough AR. Squamous metaplasia of prostate following oestrogen therapy. J Urol 1952;68:329-36.

${ }^{9}$ Sidhu GS. The endodermal origin of digestive and respiratory tract APUD cells. Histopathological evidence and a review of the literature. Am J Pathol 1979;96:5-20.

${ }^{10}$ Azumi N, Shibuya H, Ishikura M. Primary prostatic carcinoid tumour with intracytoplasmic prostatic acid phosphatase and prostate specific antigen. Am J Surg Pathol 1984;8:545-50.

${ }^{11}$ Montasser A, Ong M, Mehta V. Carcinoid tumour of the prostate associated with adenocarcinoma. Cancer 1979;44:307-10.

12 Almagro UA. Argyrophilic prostatic carcinoma. Case report with literature review on prostatic carcinoid and 'carcinoid-like' prostatic carcinoma. Cancer 1985;55:608-14.

${ }^{13}$ Sellwood RA, Spencer J, Azzopardi JG, Wapuick S, Welbourne RB, Kulatilake AE. Inappropriate secretion of antidiuretic hormone by carcinoma of the prostate. Br J Surg 1969;56:933-5.

Requests for reprints to: Dr M Stratton, Department of Histopathology, Royal Postgraduate Medical School, Hammersmith Hospital, Du Cane Road, London W12 0HS, England. 